\title{
Empirical Test of the Martingale Property in Stock Market: Evidence from Nigeria
}

\author{
Ajayi John Ayodele ${ }^{1, ~ *}$, Ojo-Agbodu Ayodele ${ }^{2}$, Adesina Nathaniel Olanrewaju ${ }^{3}$ \\ ${ }^{1}$ Department of Banking and Finance, Federal University of Agriculture, Abeokuta, Nigeria \\ ${ }^{2}$ Department of Accounting, Lagos State University, Ojo, Nigeria \\ ${ }^{3}$ Department of Entrepreneurial Studies, Federal University of Agriculture, Abeokuta, Nigeria \\ Email address: \\ ayodelejohayo@yahoo.com (Ajayi J. A.), ojoagbodu@gmail.com (Ojo-Agbodu A.), nathadesina@yahoo.co.uk (Adesina N. O.) \\ ${ }^{*}$ Corresponding author
}

\section{To cite this article:}

Ajayi John Ayodele, Ojo-Agbodu Ayodele, Adesina Nathaniel Olanrewaju. Empirical Test of the Martingale Property in Stock Market: Evidence from Nigeria. Journal of Finance and Accounting. Vol. 5, No. 4, 2017, pp. 147-150. doi: 10.11648/j.jfa.20170504.14

Received: October 26, 2016; Accepted: January 4, 2017; Published: June 21, 2017

\begin{abstract}
This paper investigates whether the martingale property holds in the Nigerian stock market. A transfer function approach was utilized for the study in which a martingale specification framework was constructed to check if the martingale property holds in line or against the specification conditions for the transfer function technique in the Nigerian stock market. Daily returns from the Nigerian stock market spanning January 1, 2005 to December 31, 2013 were used for the study. Findings from the study revealed that the Nigerian stock market does not exhibit martingale property and hence is weak- form inefficient.
\end{abstract}

Keywords: Martingale Property, Martingale Specification, Transfer Function, Stock Market

\section{Introduction}

[1] was the proponent of the martingale model. He used the model as an alternative to Random Walk Model formulated by Bachelier in 1900. [1] opined that properly anticipated prices fluctuate randomly and that the martingale model provides a precise way in which information is reflected in asset prices [2].

The martingale model is a relaxed version of the Random Walk, and is better suited for financial time series which shows a strong degree of heteroskedasticity. Therefore if the time series of an asset price follows a martingale, then its return is purely non-predictable and investors are unable to make abnormal returns consistently over time [3].

[4] opined that a capital market is a martingale, that is, fair game. He implicitly assumes that all individuals have the same information functions and at least conditional on the information under consideration, they share the same beliefs. This allows him to use the terms efficient capital markets without any ambiguity.

According to [4], the fair game means that information cannot be used to profit in the market. It requires that traders be rational in order to achieve price equilibrium. It does not require independence through time or accept only the independently and identically distributed (IID) observations. If returns are random, then markets are efficient. But, when markets are efficient, the returns are not necessarily random. Martingale also implies that past price series were not related to future prices. The current prices fully reflect all past price series so that the knowledge of that series has no value in forming expectations about future prices. The fair game model does not require independently and identically distributed (IID) assumption like the Random Walk. Price changes will be random only because of the evaluation of the random changes in fundamentals of a firm, not the random pattern of price changes.

A lot of empirical studies have been done in developed countries on testing the martingale property but not much has been done for developing countries of which Nigeria is one, this motivates the researchers to embark on the study and also there has not been consensus among the previous works. However, the remainder of the paper are as follows: literature review, methodology, data, sampling size and technique, empirical results and discussion as well as conclusion. 


\subsection{Objective of the Study}

The main objective of this study is to empirically determine whether the Nigerian stock market has martingale property

\subsection{Research Hypothesis}

To accomplish the above objective, the hypothesis below which is in null form is formulated and tested for the study.

$\mathrm{Ho}_{1}$ : There is no presence of martingale property in the Nigerian stock market.

\section{Literature Review}

There have been numerous empirical studies which test for the martingale property in stock prices. Notable examples include [5, 6] for Western countries; [7, 8, 9, 10 \& 11] among others for Asian countries. Some recent works on martingale property include [12 \& 13] among others. However, there has not been consensus among these studies.

A martingale is a special case of weak- form of market efficiency which says that the expected next future price is equal to the current price. It is a market of interest for many finance practitioners and scholars [14]. Martingale is also a mathematical form used to describe a stochastic process (a collection of random variables indexed by time) where past occurrences are not predictive of future occurrences [15].

[1] proved the proposition that properly anticipated prices fluctuate randomly. Thus, with simple assumptions randomness can be linked with the basic elements of economic equilibria including preferences and returns. It provides a precise way in which information is reflected in the asset prices. A stochastic process, $\mathrm{xt}$ is a martingale within an information set, It if the best forecast of $x t+1$ based on current information, It would be equal to $\mathrm{xt}$, or formally, Martingale $(\mathrm{xt}+1 \mid I \mathrm{t})=\mathrm{xt}$ or conditionally expected returns are constant. [1] combines an assumption equivalent to one of perfect capital markets with the assumption that the security price at any point in time is equal to the market's expectation of all future dividends discounted at a constant rate:

$$
P j t=\Sigma E[x j t+T(1+r j)-T
$$

Where:

$\mathrm{Pjt}=$ equilibrium price of security $\mathrm{j}$ at time $\mathrm{t}$,

$\mathrm{xjt}+\mathrm{T}=$ uncertain dividend paid on security $\mathrm{j}$ at time $\mathrm{t}$,

$1+\mathrm{rj}=$ discount rate appropriate to security $\mathrm{j}$,

$\mathrm{T}=$ conditional expectation on the information available at $\mathrm{t}$.

The martingale property of security price states that at any point in time, the equilibrium price is set such that the expected one period security return is equal to the discount rate. That is, the expected security return conditional on the information available at time $t$ is equal to the unconditional discount rate.

\section{Methodology}

In accordance with [16], the researchers develop a Transfer
Function (TF) model. The general form of this model takes the following form:

$$
M k t_{\text {ind(t) }}=f\left(\mathrm{CS}_{\text {ind11, }}, \mathrm{CS}_{\mathrm{id} 2 t}, \mathrm{CS}_{\mathrm{nt}}\right)+\mu_{\mathrm{it}}
$$

Where:

$\mathrm{Mkt}_{\text {ind }}$ is the market index representing the output series

$\mathrm{CS}_{\mathrm{nt}}$ is the computed selected securities index representing the nth publicly information i.e. the input series or causor series.

A martingale specification is constructed for the study to check if the martingale property holds in line or against the specification conditions for the transfer function technique in the Nigerian stock market. Therefore, relying heavily on [1] and [16], the proposed martingale specification can be expressed as:

$$
\begin{aligned}
\mathrm{Mkt}_{\text {ind (t) }}=\lambda_{1} \Delta_{\text {mon (t) }} & +\lambda_{2} \Delta_{\text {Tue (t) }}+\lambda_{3} \Delta_{\text {Wed (t) }}+\lambda_{4} \Delta_{\text {Thur (t) }} \\
& +\lambda_{5} \Delta_{\text {Fri (t) }}+\mu_{7 \mathrm{t}}
\end{aligned}
$$

Where: $\mathrm{Mkt}_{\text {ind (t) }}$ is the output series used in the TF model.

$\Delta_{\text {mont }}$ takes values between 1 and 0 ; it is 1 on Monday but zero every other day.

$\Delta_{\text {Tue (t) }}$ takes values between 1 and 0 ; it is 1 on Tuesday but zero every other day.

$\Delta_{\text {Wed (t) }}$ takes values between 1 and 0 ; it is 1 on Wednesday but zero every other day.

$\Delta_{\text {Thur (t) }}$ takes values between 1 and 0 ; it is 1 on Thursday but zero every other day.

$\Delta_{\text {Fri (t) }}$ takes values between 1 and 0 ; it is 1 on Friday but zero every other day.

While $\lambda_{1}, \lambda_{2}, \lambda_{3}, \lambda_{4}, \& \lambda_{5}$ are the coefficients associated with Monday, Tuesday, Wednesday, Thursday and Friday respectively.

On the a-priori, $\mathrm{Mkt}_{\text {ind (t) }}$ will be considered to have a unit root or martingale property if one of these two conditions holds:

i All the estimated coefficients in equation 2 are statistically significant. In which case there is significant difference among the estimated parameters. That is $\Delta_{\text {Mon (t) }}=\Delta_{\text {Tue (t) }}=\Delta_{\text {Wed }}=\Delta_{\text {Thur (t) }}=\Delta_{\text {Fri (t) }}$ and the residual term $\mu_{7}$ under the OLS classical assumption is normally and independently distributed about a zero mean with constant variance. That is $\mathrm{E}\left(\mu_{\gamma_{\mathrm{t}}}\right)=0 ; \mathrm{E}\left(\mu_{7 \mathrm{t}}\right.$, $\left.\mu_{7 \mathrm{t}}+1\right)=0$ for all $\mathrm{i} \neq 0$ and $\mathrm{E}\left(\mu_{7 \mathrm{t}}\right)^{2}=\delta^{2}$

Thus:

$$
\mathrm{E}\left(\mathrm{Mkt}_{\mathrm{ind}}\right)=\mathrm{E}\left(\lambda \Delta_{\mathrm{t}}\right)+\mathrm{E}\left(\mu_{7 \mathrm{t}}\right)
$$

Where: $\Delta_{\mathrm{t}}$ is a series of $1, \Delta_{\mathrm{t}}=1$ for Monday through Friday.

$\lambda$ is the estimated value for all the $\lambda_{i}$ 's coefficients

$$
\mathrm{E}\left(\mathrm{Mkt}_{\mathrm{ind}(\mathrm{t})}\right)=\lambda+0
$$

Note also that $\lambda$ is a constant if all the parameters in equation 2 are significant. Thus:

$$
\mathrm{E}\left(\mathrm{Mkt}_{\mathrm{ind}(\mathrm{t})}\right)=\mathrm{constant}
$$

But if the residual in equation 2 is not white noise, then: 


$$
\mathrm{E}\left(\mathrm{Mkt}_{\text {ind }(\mathrm{t})}\right) \neq \text { constant }
$$

ii All the estimated parameter or coefficients in equation 2 are statistically not different from zero but the residual term $\left(\mu_{7 t}\right)$ is identically and independently (IID) distributed. That is it is white noise. In this context,

$$
\mathrm{E}\left(\mathrm{Mkt}_{\text {indt }}\right)=\mathrm{E}\left(\mu_{7 \mathrm{t}}\right)
$$

Since $E\left(\mu_{7 t}\right)=0$, then

$$
\mathrm{E}\left(\mathrm{Mkt}_{\text {indt }}\right)=0
$$

Therefore, the expected value of the market index is constant at 0 , we can now state the martingale condition as follows:

That the series of the market index does not satisfy either condition (i) or (ii); concerning the martingale property.

It is presumably assumed that the holiday and weekend effects will induce missing values in the set of observation. To deal with this problem, we introduced intervention model to the output and input series in the TF model discussed earlier.

$$
\begin{gathered}
\mathrm{Mkt}_{\text {ind (t) }}=\mathrm{BCS}_{\text {ind (t) }}+\mu_{14} \\
\mathrm{Mkt}_{\text {ind (t) }}=\frac{\mathrm{BCS}_{\text {ind (t) }}}{\left(1-\partial_{1} \mathrm{~L}\right)}+\mu 14
\end{gathered}
$$

Where: $\mathrm{Mkt}_{\text {ind (t) }}$ is the time series to be modelled.

$\mathrm{CS}_{\text {ind (t) }}$ is the intervention time series (Input series) and it is equal to 1 for missing value but otherwise.

\subsection{Data}

Data for the study were daily returns from the Nigerian Stock Exchange and they were obtained from the Daily Official List of the Nigerian Stock Exchange as well as the Nigerian Stock Exchange Fact Book spanning the period of 2005-2013.

\subsection{Sampling Technique and Size}

The population for this study encompasses all the companies that traded in the Nigerian stock market from the period of January 1, 2005 to December 31, 2013. All these companies are ranked according to their capitalization and a random sampling technique is employed to select the companies that have the capitalization values above the average value. Thus, about 80 companies qualified for this sample size. The reason for this is that those companies whose capitalization is below the average values are expected to be dwindling companies within consisted trading strategy. Therefore, incorporating such companies in the sample size may distort regression results or at worse may yield spurious estimations.

\section{Empirical Results and Discussion}

Hypothesis Testing: There is no presence of martingale property in the Nigerian stock market.

To test this hypothesis, the researchers estimate equation 2 and then subject it to Breusch-Godfrey Serial Correlation LM Test. The estimated results of equation 2 and the corresponding LM test are presented in tables 1 and. 2 respectively.

Table 1. The Result of the Test Conducted on the Presence of no Martingale Property in the Nigerian Stock Market.

\begin{tabular}{lllll}
\hline Variable & Coefficien & Std. Error & t-Statistic & Prob. \\
\hline MON & 31144.97 & 568.2080 & 54.81263 & 0.0000 \\
TUE & 31098.74 & 567.5560 & 54.79414 & 0.0000 \\
WED & 31160.67 & 568.8622 & 54.77718 & 0.0000 \\
THUR & 31163.84 & 568.8622 & 54.78276 & 0.0000 \\
FRI & 31207.87 & 568.2080 & 54.92333 & 0.0000 \\
\hline
\end{tabular}

Source: Summarized by the Authors from E-view Window 8

Table 1 above shows the estimated values of equation 2 . As revealed in this table, all the computed t-values are larger than the critical t-value (1.29). This means all the parameters are significantly different from zero. Therefore, the market does not possess martingale property and hence is weakform inefficient. However, to confirm the above test further, the researchers adopt the LM Serial Correlation Test by Breusch-Godfrey and the results of the Test are summarized in table 2 below.

Table 2. The Result of the Breusch-Godfrey Serial Correlation LM Test.

\begin{tabular}{llll}
\hline F-statistics & 996572.2 & Prob. F (2, 2167) & 0.0000 \\
Obs*R-squared & 2171.639 & Prob. Chi-Square (2) & 0.0000 \\
\hline
\end{tabular}

Source: Summarized by the Authors from E-view Window 8

The LM serial correlation test results are presented in Table 2. The F-statistics and Chi-square statistics are asymptotically large with probability value of 0.000 meaning that they are big. Therefore, there is sufficient evidence to reject the null hypothesis that the residual term is not serially correlated. The successive error terms are not randomly distributed. Since the error term is not purely random, the claim that the market index is constant is imprecise and there is no evidence of the presence of martingale property in the market.

\section{Conclusion}

In this paper an attempt has been made to examine the martingale property in the Nigerian stock market. The authors obtained secondary data from the daily returns of the Nigerian stock market spanning the period of 2005-2013. The absence of consensus in the literature coupled with few studies in developing countries provide a compelling motivation to examine specifically the empirical test of martingale property in the Nigerian stock market. All the companies that traded in the Nigerian stock market constitutes the population of the study and the companies are ranked according to their capitalization and a random sampling technique was used to select the companies that have their capitalization above the average value of which about 80 companies qualified for the sample size. A transfer function technique was applied for the study and a martingale 
specification framework was constructed to examine whether the martingale property holds in the Nigerian stock market. The hypothesis formulated for the study was tested and results obtained showed that all the computed t-values are larger than the critical t-value at $10 \%$ significance level. The hypothesis was further subjected to Breusch Godfrey Correlation LM Test. Results from the study showed that the Nigerian stock market does not exhibit martingale property.

\section{References}

[1] Samuelson, P. A (1965). Proof that properly anticipated price fluctuate randomly, Industrial Management Review, 6: PP 4149.

[2] Leroy, S. F. (1989). Efficient capital markets and martingales, Journal of Economic Literature. Vol. 27, No. 4, PP 1583-1621.

[3] Kim, J. H (2004). Testing the martingale hypothesis in Asian stock prices: Evidence from a new joint variance ratio test, Department of Econometrics and Business Statistics, Monash University, Australia.

[4] Fama, E. F. (1991). Efficient capital markets: II, Journal of Finance, 46 (5, December): PP 1575-617.

[5] Lo, A. and Mackinlay, A. C (1988). Stock market prices do not follow random walk: Evidence from a simple specification test. Review of Financial Studies 7 (3): PP 1-8.

[6] Kim, M. J. (1991): Mean Reversion in Stock Prices? A Reappraisal of the Empirical Evidence, Review of Economic Studies, 58: PP. 515-528. Frennberg \& Hansson (1993).

[7] Ayadi, O. F. and Pyun, C. S (1994). An application of variance ratio test to the Korean securities market. Journal of Banking and Finance, 18 (4): PP.643-658.
[8] Huang B. N. (1995): Do Asian stock market prices follow random walk? Evidence from variance ratio test, Applied Financial Economics, 5: PP. 251-256.

[9] Malliaropulos, D., \& Priestley R. (1999): Mean revision in Southeast Asian stock markets, Journal of Empirical Finance, 6: PP 355-384.

[10] Chang, K. P. \& Ting K. S (2000): A variance ratio test of the random walk hypothesis for Taiwan's stock market, Applied Financial Economics, 10: PP.525- 532.

[11] Ryoo, H. J. \& Smith, G. (2002): Korean Stock prices under price limits: variance ratio Tests of random walks, Applied Financial Economics, 12: PP. 475-484.

[12] Nankervis, J. C. \& Savin, N. E. (2010). Testing the serial correlation generalized Andrews- Ploberger tests, Journal of Economic and Business Statistics 28, PP. 246-255.

[13] Peter, C. B. \& Sainan, J. (2013). Testing the martingale hypothesis, Cowles Foundation Discussion Paper No. 1912, Yale University, New Haven.

[14] Pham, T. P., Kim, J. H. \& Jurdi, D. (2015). Stock return weakform efficiency of ASEAN stock markets, Department of Economics, La Trobe University, Australia.

[15] Bilello, C. (2016). Martingales and markets accessed on-line (a) http://pension Partners. com/martingales on $19^{\text {th }}$ November.

[16] Joseph, W. C. (1986). An alternative semi-strong form test of the efficient market hypothesis by a transfer function approach, Unpublished MBA Dissertation, Simon Fraser University, Canada. 